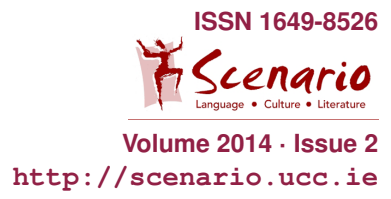

Conference Report

\title{
Performing a conference: SCENARIO Forum 2014
}

\author{
Silja Weber
}

"Finally a place where I don't have to explain the basics of what I do. Now we can get to the interesting questions!" was one common tenor in the many fascinating conversations I found myself having at the SCENARIO Forum conference. In various different keys, this sentiment wove through the papers, presentations, and workshops by applied theatre practitioners, performance artists, foreign language teachers/researchers representing a spectrum of languages and age groups from preschool to university, drama teachers, researchers from areas like second language studies, neuroscience, and cultural and literary theory, education specialists, and various hybrids of those categories.

The SCENARIO Forum International Conference on Performative Teaching, Learning, and Research was held May 29-June 1, 2014, on the campus of University College Cork (UCC), Ireland. It was, in a way, the live manifestation of the work of Manfred Schewe (UCC) and Susanne Even (Indiana University Bloomington, IN, USA), who co-founded the online journal SCENARIO ${ }^{1}$ in 2007 and have co-edited it ever since. The focus of the journal is the use of drama and theatre in additional language teaching and it has cultivated a diversity of perspectives and genres since its inception, not least by being bilingual (German/English). It is the only peer-reviewed journal aimed specifically at the intersection of performance and foreign language learning research. The conference was co-organized by Even and Schewe, assisted with skill, dedication, and good humour by Micha Fleiner, Stefan Kriechbaumer and Niko Preuschoff, and it clearly reflected the profile of the journal: It was also bilingual, the nearly 100 presenters came from 19 countries on four continents, and the presentations ranged in format from three evening performances of different types over 14 workshops to more than 50 (not only) theoretical papers as well as four keynote speeches by Mike Fleming (Durham University, UK), Peter Lutzker (Freie Hochschule Stuttgart, Germany), Michaela Sambanis (Freie Universität Berlin, Germany), and Florian Vaßen (Leibniz Universität Hannover, Germany).

It is worth emphasizing that less traditional formats in this range were well represented. For example ${ }^{2}$, there were hands-on workshops on the use of drama for work with gangs, voice work, performance of gender and queer identities in the classroom, and spoken language learning activities building on

\footnotetext{
${ }^{1}$ See http://scenario.ucc.ie (Accessed 6 January 2015).

${ }^{2}$ For clarity's sake, I do not cite all presenters here; this information, including all presentation abstracts, can be found on the SCENARIO Forum website, http://www.ucc.ie/en/ scenario/scenarioforum/scenarioforum-conference2014/ (Accessed 6 January 2015).
} 
improvisation; there were papers including performed spoken word poetry or video material from hybrid classroom formats like lecture performance; there was a report on a translingual teaching project involving actors and teachers; there were a stunning example of performed research and a fun evening of interactive improvisational theatre.

Interaction was itself a major feature of the conference. Even Peter Lutzker's keynote address and Even and Schewe's introductory presentation involved audience participation. A frequently paraphrased comment during the panel sessions was, "We are at a conference on performance in teaching, and we are still sitting in our chairs?!" In my opinion, there was a lot less sitting and quite a bit more interaction and movement than conferences usually offer. This was due partly to the fact that people who teach (via) drama are likely by definition to be somewhat socially adventurous; due partly to the thematically mixed panels, a feature which was mirrored in the mixed backgrounds of attendees; and not least due to the friendly atmosphere created both by the organizers and by the location itself: a good portion of the break times was spent in and around the beautiful Granary Theatre, where the enclosed courtyard and two big meeting rooms invited informal conversations over the tasty sandwiches provided there. In fact, at times, the conference had a festival feeling to it, and this perspective is well represented in the short film documenting the conference. ${ }^{3}$

However, there was a great amount of theoretical work going on as well. "Here we can get to the interesting questions!" said my conversation partners. What were the questions being discussed?

A very intriguing aspect for me was that there were several levels of discussion, even within one angle on the topic. For example, if you gather a horde of teachers, you will always have an exchange at the micro-level of techniques and activities. I found myself jotting down notes on how to organically include practice of the past tense in improvisational activities. There was also the omnipresent question of how to make room for performative teaching in our specific institutional environments - but also, on a much larger scale, in the case of Mike Fleming's keynote address, how to integrate it into the higher echelons of educational planning. In several presentations on the relationship between pedagogy and second language acquisition, the following questions surfaced: What exactly are the effects of using drama and theatre pedagogy in terms of improved language skills? On the methodological level, (how) is it possible to investigate and measure those effects in experimental studies? From another perspective allied to 'hard science', addressed in Michaela Sambanis' keynote speech: Which neurological insights might help explain why we see the positive effects of performative pedagogy that we find cited so often, and how transferable are traditional lab results when we study specific classroom environments? In the critically oriented direction: How do we make language accessible via drama and theatre to students outside the humanities or the classroom, and how do we foster inclusion (e.g. in terms of multilingual

\footnotetext{
${ }^{3}$ See https://www.youtube.com/watch?v=3dhpa6Yz5_M (Accessed 6 January 2015).
} 
theatre or queer identities)? How do teachers see their own involvement in performative pedagogy, and how do we use it in teacher training? If we use drama techniques in language classes, do we reproduce outworn dramatic structures, or can we move on into 'post-dramatic' techniques? How can we deconstruct not only dramatic structure, but also our preconceptions of 'what drama does'? And what, incidentally, do drama and theatre pedagogy do, for example in terms of the development of identity and symbolic competence? On the purely conceptual level, describing a field striving to grow and define itself: Do we need a concept of 'performative' pedagogy, rather than a spectrum of drama and theatre approaches? Does a unified label clarify or obscure our purposes? How does the performative in pedagogy relate to performativity in other fields? - And why are we still sitting in our chairs?

Additionally, there was a note linking many presentations, especially of presenters who have lived with some of these questions for a long time: something like a pedal point calling for time, for silence, for careful listening, observing, and understanding; for "experiencing and practicing rather than training" (Peter Lutzker), extending to all participants in the teaching/learning process. That this deeper note was successfully struck and held through a busy conference weekend is remarkable. A reincarnation of the humanist ideal of supporting the development of the whole individual, beleaguered on many fronts in most formal teaching contexts, was alive and well in Cork. The SCENARIO Forum conference provided the kind of environment that can build communities; an environment that can nourish both a creative, (self-)critical exchange and a reaffirmation of the passions that move us to perform our identities as teachers, artists, and researchers in the first place.

I hope this environment will be provided again in the coming years.

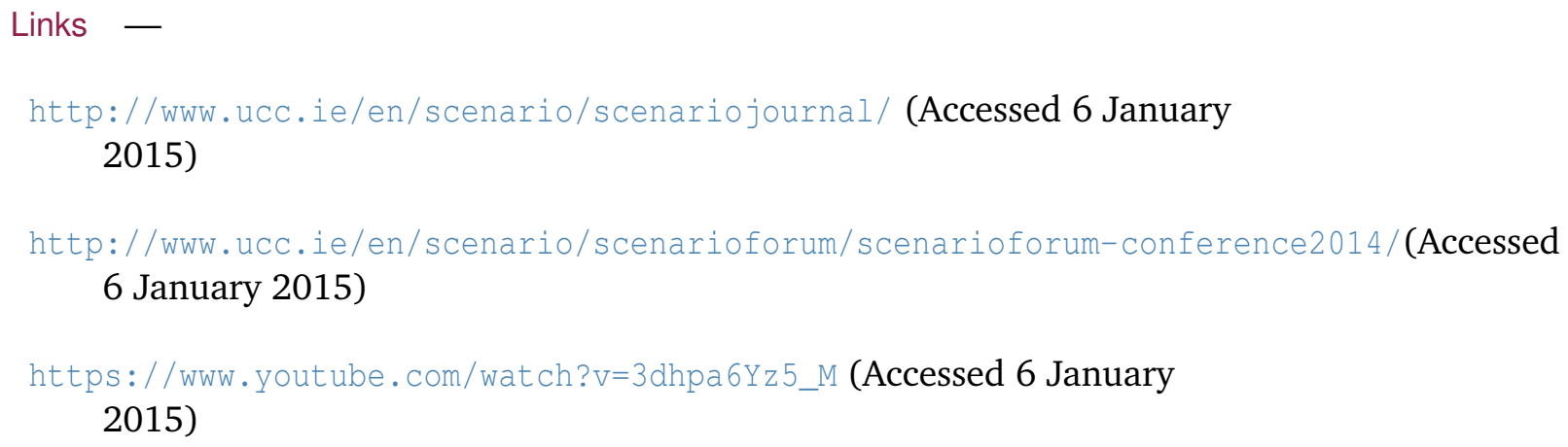

